\title{
Impact of modelling scale on probabilistic flood risk assessment: the Malawi case
}

\author{
Roberto Rudari $^{1, a}$, Joost Beckers ${ }^{2}$, Silvia De Angeli ${ }^{1,3}$, Lauro Rossi ${ }^{1}$, Eva Trasforini ${ }^{1}$ \\ ${ }^{1}$ CIMA Research Foundation, Via Armando Magliotto, 2, I-17100 Savona, Italy \\ ${ }^{2}$ Deltares, P.O. Box 177, 2600 MH Delft, The Netherlands \\ ${ }^{3}$ Institute for Advanced Study of Pavia, Palazzo del Broletto, Piazza della Vittoria, 15, I-27100 Pavia, Italy
}

\begin{abstract}
In the early months of 2015, destructive floods hit Malawi, causing deaths and economic losses. Flood risk assessment outcomes can be used to increase scientific-supported awareness of risk. The recent increase in availability of high resolution data such as TanDEM-X at $12 \mathrm{~m}$ resolution makes possible the use of detailed physical based flood hazard models in risk assessment. Nonetheless the scale of hazard modelling still remains an issue, which requires a compromise between level of detail and computational efforts. This work presents two different approaches on hazard modelling. Both methods rely on 32-years of numeric weather re-analysis and rainfall-runoff transformation through a fully distributed WFLOW-type hydrological model. The first method, applied at national scale, uses fast post-processing routines, which estimate flood water depth at a resolution of about $1 \times 1 \mathrm{~km}$. The second method applies a full 2D hydraulic model to propagate water discharge into the flood plains and best suites for small areas where assets are concentrated. At the $12 \mathrm{~m}$ resolution, three hot spots with a model area of approximately $10 \times 10$ $\mathrm{km}$ are analysed. Flood hazard maps obtained with both approaches are combined with flood impact models at the same resolution to generate indicators for flood risk. A quantitative comparison of the two approaches is presented in order to show the effects of modelling scale on both hazard and impact losses.
\end{abstract}

\section{Introduction}

Starting from the end of 2013, the European Union (EU) put a strong effort in improving the understanding of risks related to natural hazards in Africa through the ACP funding instrument. This effort has been catalysed by the increasing risk in the region, materializing through natural hazard extremes. These Natural risks are a hurdle to the development of many African countries that see GDP and investments eroding every year because of the impact of such natural hazards. Specifically, in January 2015 and continuing through February, Southern Malawi was hit by severe floods caused by a large low pressure system that continued to generate heavy rains over the area. The Shire River south of Lake Malawi and tributaries flooded large parts of the country in several flood waves. More than 170 people lost their lives, thousands were displaced and crops were lost.

While assessing the post-disaster needs and trying to recover from the floods it was found that the existing flood hazard map for Malawi was not adequate. This map is based on the SRTM90m and covers only part of the country. The World Bank has therefore put forward a request to compute improved flood hazard maps covering the Norther part of Malawi on a higher resolution.

The hazard flood maps represent the basis for a preliminary risk assessment work that would produce risk figures that will be primarily used to increase scientificsupported awareness at governmental level about country level and sub-country level risks.

Risk financing could play a key role in protecting the investments and can lead the way to a future where such risk is understood, reduced and controlled. The first step along this path is to understand the underlying risk that the country of Malawi faces.

In order to achieve these results, global open data, such as globally available forcing data, and exposure datasets, if possible complemented by open local data sets, will be used so that the obtained results can be shared publicly after the project has been completed. For GDP data we will rely on GFDRR to provide the most appropriate and updated dataset, while for the other assets, including critical infrastructure will be taken from available exposure datasets.

One of the innovation presented in this work is related to the use of a high resolution DEM, such as TanDEM-X. One of the challenges to applying DTMs to real flooding scenarios has been the absence of the availability of a standard DTM at a sufficient level of resolution. Low resolution DEMs such as the STRM $90 \mathrm{~m}$ version are globally available free of charge, but offer limited use for flood modellers in most geographic areas, either because of the errors in water flow or the inability to distinguish critical urban infrastructure. With the advent of

\footnotetext{
${ }^{\mathrm{a}}$ Corresponding author: roberto.rudari@cimafoundation.org
} 
commercially available DEMs at higher resolution such as the TANDEM-X DEM at $10-12 \mathrm{~m}$ resolution, significant progress will be possible through the application of these technologies to risk assessment. The outstanding characteristics of TanDEM-X are the provision of a truly global and homogenous data set and greatly improved spatial and vertical resolution. Recent analysis comparing DTMs ranging from $1 \mathrm{~m}$ to $90 \mathrm{~m}$ resolution have shown that DTMs offering around $10 \mathrm{~m}$ resolution are the most useful for flood modelling, with $50 \mathrm{~m}$ and $90 \mathrm{~m}$ models being too coarse and the $1 \mathrm{~m}$ model requiring too much computation time for only marginally better results. The global coverage TanDEM-X offers high precision elevation information in areas above $60^{\circ}$ latitude that were not covered by SRTM before. It also facilitates the transfer of risk mitigation and vulnerability assessment techniques, enabling truly global applications.

\section{Hazard modelling framework}

The flood mapping framework is depicted in

Figure 1. This flow chart shows there are two different approaches on hazard modelling, which are used to assess riverine flood risk at different scale in Malawi. Both methods rely on 32-years of statistical analysis of the EU-WATCH rainfall data and rainfall-runoff transformation through a fully distributed WFLOW-type hydrological model (GLOFRIS) [1,2].

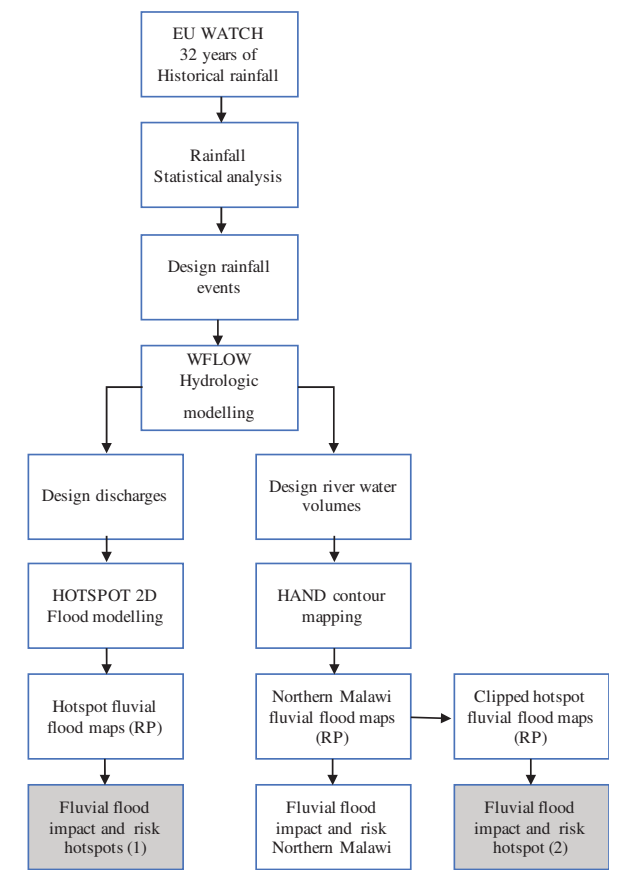

Figure 1 Flood mapping flow chart.

The first method applies a full 2D hydraulic model (D-Flow Flexible Mesh) to propagate water discharge into the flood plains and best suites for small areas where assets are concentrated. At the $12 \mathrm{~m}$ resolution, three hot spots with a model area of approximately $10 \times 10 \mathrm{~km}$ are analysed.

The second method, applied at national scale, uses fast post-processing routines, which estimate flood water depth at a resolution of about $1 \times 1 \mathrm{~km}$. Next, a downscaling technique gradually distributes water volumes over the TanDEM-X terrain model to obtain inundation maps at target resolution of 12 meters [2]. This method is applied for the entire study area, which covers the northern part of the country (mainly North and Central Malawi). The hazard and the derived risk maps obtained from this approach can be compared, in correspondence to the hotspots, with those produced with the 2D model for the same sites.

The impact in both cases is evaluated in terms of expected economic loss, applying the methodology described in part 5 .

\subsection{Meteorological forcing}

Rainfall and (potential) evapotranspiration (PET) are the two main driving forces for the hydrologic model to simulate surface runoff and river discharge. The rainfall input was obtained from the freely available EUWATCH dataset $[3,4]$. This set was produced as part of the EU FP6 'WATCH' project for regional and global studies of climate and water. The EU-WATCH dataset describes rainfall at 3 hours temporal and $\sim 50 \mathrm{~km}$ spatial resolution for the full 20th century (1900-2001). However, a test run of the hydrological model revealed that the pre-1970 rainfall over Malawi has a different distribution with higher average flows. Probably, the post-1970 rainfall was bias-corrected by using a data source that was not available before 1970. The pre-1970 data was therefore excluded from the analyses.

The EU-WATCH annual rainfall between 1970 and 2001 (32 years) was validated against rainfall measurements at ground gauges. The gauge stations at Lilongwe, the capital of Malawi, and Mzuzu were considered most reliable and were selected for this validation.

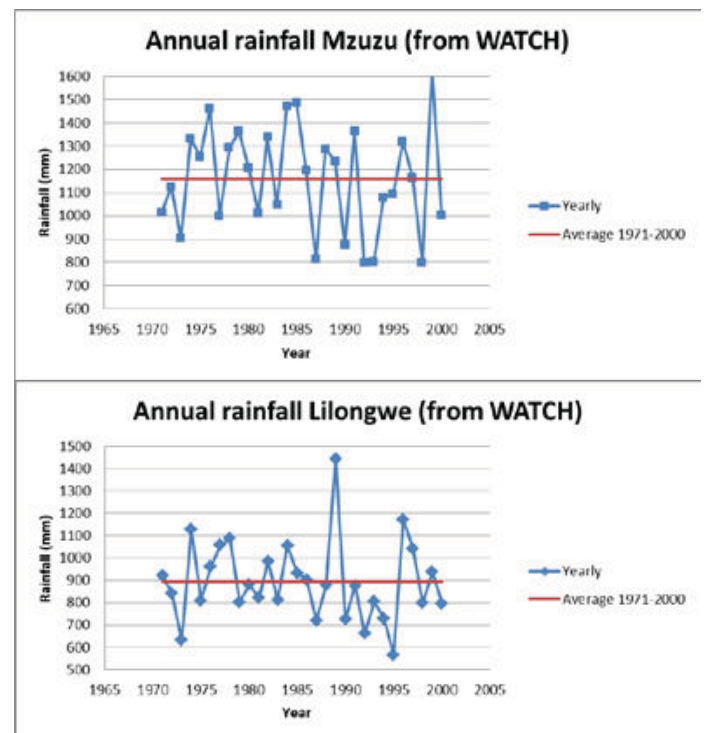

Figure 2 Lilongwe and Mzuzu annual rainfall from EUWATCH.

For Lilongwe, the average EU-WATCH annual rainfall between 1970 and 2000 was 899 mm/yr (Figure 2). For Mzuzu the average is $1159 \mathrm{~mm} / \mathrm{yr}$. These values correspond reasonably well with the $900 \mathrm{~mm} / \mathrm{yr}$ for Lilongwe and 1289 for Mzuzu as reported by the Malawi 
Department of Climate Change and Meteorological Services ${ }^{1}$.

The Potential Evaporation-Transpiration (PET) for Malawi was taken from Ngongondo et al. [5], who derived an average PET of $2.9 \mathrm{~mm} /$ day, based on a 30year surface water balance study.

\subsection{Rainfall statistical analysis}

To force the hydrologic model, a design rainfall event for every return period is needed. This was derived from Intensity-Duration-Frequency (IDF) rainfall statistics. The IDF-table or IDF curve is a common representation of the probability of exceedance of rainfall thresholds over a given duration. The 32-year EU-WATCH data at 3-hour temporal resolution were used to derive IDF curves for northern Malawi.

The IDF curves were obtained for several locations spread over northern Malawi and mutually compared. The average over all stations was taken to obtain an average location IDF (Figure 3).

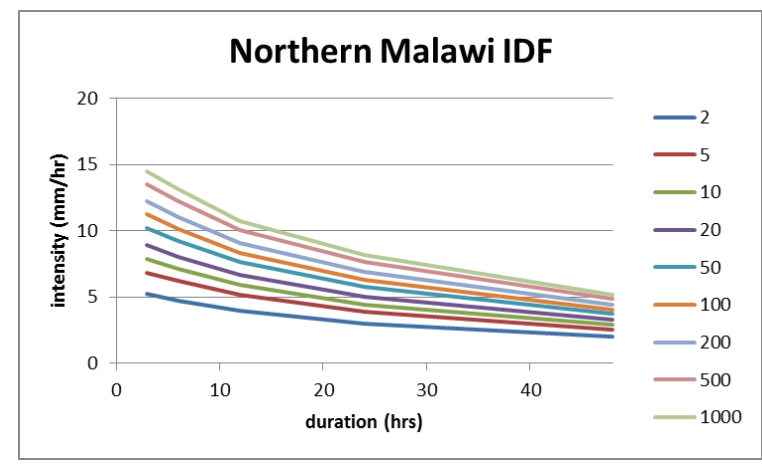

Figure 3 Average IDF curves for all stations over northern Malawi. Each graph represents a return period (shown in the legend in years).

An empirical formula (known as Wisner's formula) was fitted to the IDF table data:

$$
i=\frac{a}{\left(t_{d}+b\right)^{c}}
$$

Where:

$\mathrm{t}_{\mathrm{d}}=$ duration (minutes)

$\mathrm{i}=$ average intensity in period $\mathrm{td}(\mathrm{mm} / \mathrm{hr})$

$\mathrm{a}, \mathrm{b}, \mathrm{c}=$ parameters, depending on the return period $\mathrm{T}$

Next, a design rainfall event, or hyetograph, was derived from the IDF curves using the 'alternating block method', as described in Chow et al. [6]. Contiguous blocks of rainfall are added on alternating sides of the storm peak such that the total rainfall depth always matches the average intensity over the total duration given by the IDF. The temporal resolution of the hyetograph is 1 hour and the total duration is 100 days, so the IDF curves were extrapolated to shorter and longer time scales.

This design hyetograph was applied as uniform rainfall over the total area (northern Malawi). No Areal Reduction Factor (ARF) was applied, since the simulation should produce flood maps for both smaller and larger (fast and slow responding) catchments in a single run. Neglecting the ARF is expected to have a relatively small effect, because the ARF is typically around 0.9 for rainfall of longer duration $(>24 \mathrm{hrs})$.

\subsection{Hydrological modelling}

The hydrologic modelling was done using the opensource WFLOW-HBV software that is developed by Deltares (http://www.openstreams.nl). The WFLOWHBV model is a fully distributed version of the HBV-96 model, where the original routing function (MAXBAS) was traded for a kinematic wave function [7]. The workflow is shown in Figure 4.

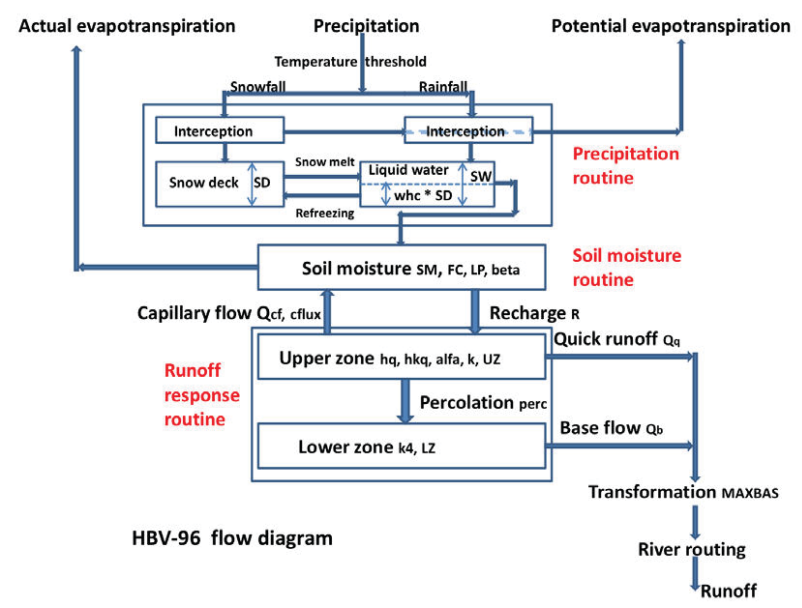

Figure 4 General representation of the distributed WFLOW rainfall runoff model (from WFLOW documentation).

The required WFLOW model parameters were taken from freely available global data sources, such as the GlobCover land cover database of the European Spatial Agency $(\mathrm{ESA})^{2}$ for land use and the FAO Harmonized World Soil Database (HWSD) and Soil $\mathrm{Map}^{3}$ for soil type. Results from earlier studies show that WFLOW produces very reasonable results by using model parameters based on these global data, without further calibration to local gauge data.

Based on the Digital Elevation Model (DEM), which was derived from TanDEM-X by a resampling to $1 \mathrm{~km}$, the local drainage direction (LDD) and sub-basins map were derived.

In very flat areas, the direction of flow is often not well-defined, which may lead to incorrect course of rivers in the model. This was solved by 'burning in' the main rivers into the DEM, i.e. artificially lowering grid points along the course of the rivers to lead the water in the right direction. The river courses were initially derived from the DEM and then corrected by hand (comparison to Google Maps). Figure 5 shows a map of the main rivers that was obtained this way.

${ }^{2}$ http://oss.deltares.nl/web/delft3d/d-flow-flexible-mesh ${ }^{3} \mathrm{http}$ ://data.fao.org/map?entryId=446ed430-8383-11dbb9b2-000d939bc5d8

\footnotetext{
${ }^{1}$ http://www.metmalawi.com/
} 


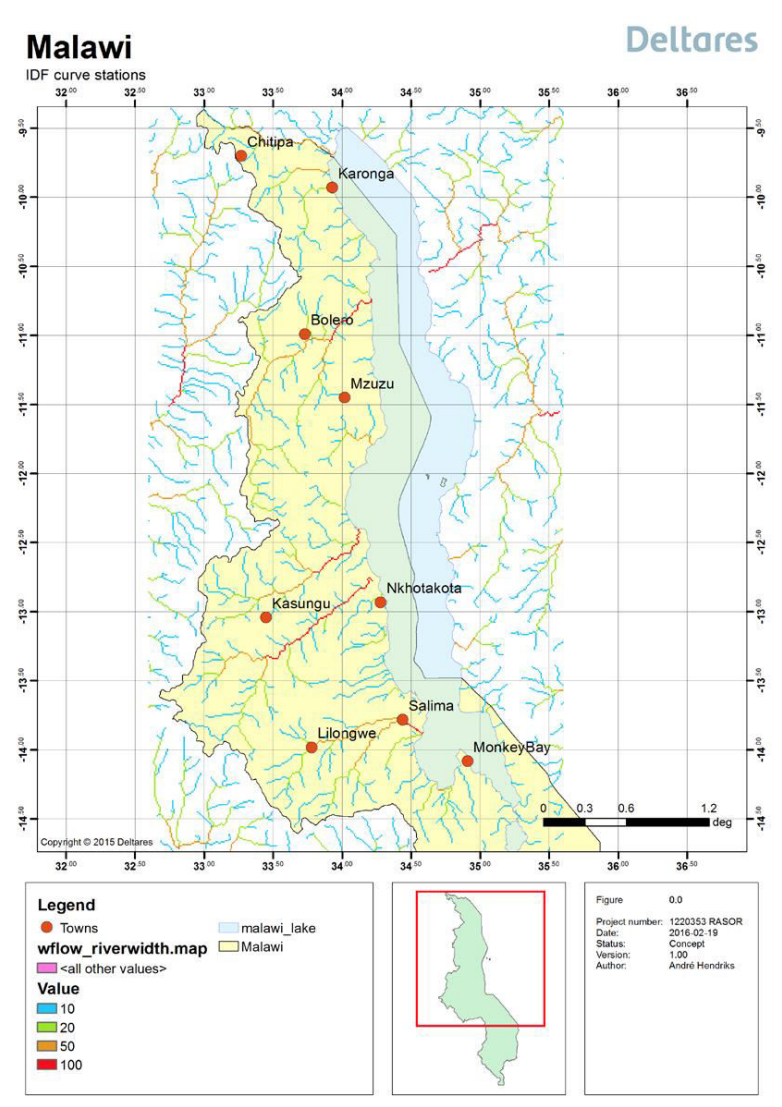

Figure 5 Main rivers in the WFLOW model.

The Malawi WFLOW-HBV model was used using as input design rainfall events for a range of return periods (2-1000 years).

\subsection{D flood modelling}

The flood maps for three hotspot areas were calculated using a model called D-Flow Flexible Mesh $(\text { D-Flow FM })^{4}$. This open source software engine for hydrodynamic simulations is being developed by Deltares.

D-Flow FM is a shallow-water solver based on the finite-volume method applied on unstructured grids.

It solves the full Saint-Venant equations and thus guarantees conservation of mass and momentum, while also accurately representing the drying and flooding of grid cells $[8,9]$.

D-Flow FM uses a flexible mesh and a variable grid resolution. This enables the modeler to use a higher resolution and more accurately simulation of the flow of water in topographically complex areas, while keeping the rest of the model at a lower resolution for optimal computational performance.

The general setup of the 2D hydraulic models is as follows:

- The terrain model is taken from the WorldDEM TanDEM-X.

- The river course (drawn by hand) is dug into the terrain, such that the $\mathrm{T}=2$ years discharge is just

\footnotetext{
${ }^{4}$ http://oss.deltares.nl/web/delft3d/d-flow-flexible-mesh
}

conveyed without bank overflow. Bankfull discharge is generally associated with a momentary maximum flow that has an average recurrence interval of 2 years [10].

- The upstream boundary conditions are derived as follows:

- Peak discharges are derived from WFLOW simulations of design rainfall events for several return periods;

- The shape of the inflow hydrograph is taken as the average shape of the four highest discharge peaks in the 32-year historical WFLOW simulations. This shape is then scaled up or down to the target peak discharge.

- The downstream boundary condition is a fixed water level (Lake Malawi, or for the Salima model a location several $\mathrm{km}$ downstream)

\subsection{HAND contour mapping}

For the whole of northern Malawi, a detailed 2D hydraulic modelling is computationally unfeasible. To produce the larger area flood maps, the surface water as calculated by the relatively coarse WFLOW hydrologic model was scaled down to the target $12 \mathrm{~m}$ resolution by using a water volume distribution scheme that is based on the Height Above Nearest Drainage (HAND). To calculate a HAND map, the difference is taken between the elevation of a given pixel and the elevation of the nearest drainage or watercourse. These watercourses are derived from the Local Drainage Direction (LDD) map using a minimum Strahler stream order threshold, so that only the main rivers are defined as watercourses.

HAND contour mapping is a static approach for mapping the potential extent of inundation that extends beyond simple mapping low-lying areas. The method does not require hydrodynamic modelling of water flow which makes it much less computationally demanding. The HAND-delineated relative height is directly related to the river stage height [11] and an effective predictor of flood potential.

The volume of surface water in $1 \mathrm{~km}$ computation cells that are part of the river network (see Figure 5) in the WFLOW model is redistributed over $12 \mathrm{~m}$ cells of the TanDEM-X as follows:

- First the riverine water volume as calculated by WFLOW (Figure 6) is reduced by the riverine water volume as calculated for the $\mathrm{T}=2 \mathrm{yr}$ rainfall event. The $\mathrm{T}=2 \mathrm{yr}$ situation is often considered the bankfull level, i.e. no flooding occurs [10]. The excess water volume above the $\mathrm{T}=2$ level is thus the water that will flood the land.

- This excess water volume is used to 'fill up' the terrain, starting from the lowest HAND contours until the mapped water volume equals the target volume. The results of this HAND contour mapping method were compared to conventional flood mapping (using 2D hydraulic models) for two hotspot areas Karonga and Salima. Results are discussed in part 3.1. 


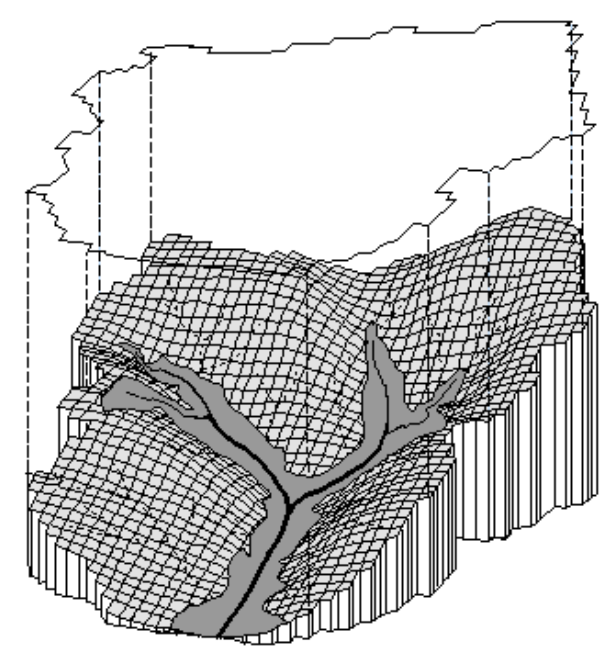

Figure 6 Schematic drawing of HAND contour surface water mapping. The areas that have the least elevation difference to a nearby drain are inundated first.

\section{Fluvial flood maps}

Fluvial flood maps were produced for a range of return periods, using WFLOW riverine water volumes and the HAND contour mapping algorithm described in section 2.5 .

Detailed inspection of the fluvial flood maps revealed that, in general, the flood maps are realistic. However, there are a few limitations and shortcomings that need to be mentioned:

\section{Fluvial flood maps account for flooding from major rivers only}

The HAND contour mapping method considers only water from the larger rivers that are defined in the relatively course hydrologic model (see Figure 5). Smaller streams and ditches that may flood during extreme rainfall events are not included in the fluvial flood mapping method.

\section{Flood level for $\mathbf{T}=\mathbf{2}$ is zero by definition}

The bank full situation is defined as the $T=2$ year flow volume. Therefore, by definition, no fluvial flooding occurs for this return period.

\section{Overestimation of inundation depths on elevated plateaus}

The HAND mapping routine uses an automated identification of rivers and streams that is derived from the LDD (local drainage direction) map. This procedure occasionally identifies a headwater as a stream. If this headwater has a local drainage area, the HAND map recognizes this as a floodable area and part of the water volume is attributed to that local drainage area. An example is given in Figure 7. A small plateau on a hillslope is recognized as a drainage area of a tributary to the larger river that runs through the valley. Part of the water volume from the larger river is attributed to the plateau. Although such areas are indeed floodable, the inundation depth is probably overestimated by the HAND mapping.

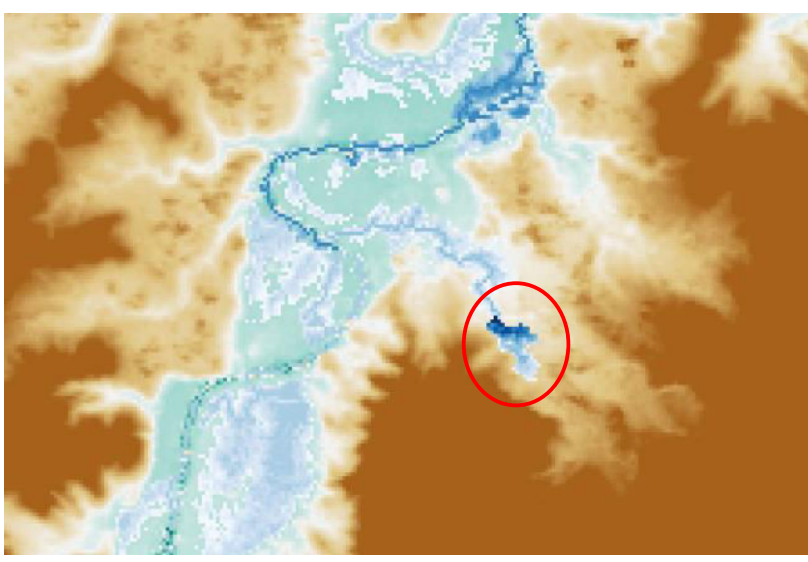

Figure 7 Local drainage area (encircled) on an elevated plateau where the inundation depth is overestimated.

\section{HAND mapping cannot reproduce complex flow patterns}

Another limitation of the HAND contour mapping is that it cannot reproduce complex flow patterns including the effect of levees. The contour mapping simply fills up the lowest areas, without considering the direction of flow. The implications of this are not that large, because most rivers and streams are natural streams and there are not that many levees. An exception is the city of Karonga, where a levee protects part of the city from flooding by the North Rukuru River. The HAND contour mapping fills up areas on both sides of the levee, because both sides have a low elevation. In reality, the levee will hold back the water that is coming from the west and the east side will stay dry until the levee overflows.

\section{Erroneous flooding near lake shores}

Lake Malawi was masked out from the inundation maps because the TandDEM-X is very noisy over open water. This causes issues at the lake shores. In some cases, water that is likely to flow into the lake is forced back onto the terrain and therefore causes unlikely flood patterns near the lake shore. An example is given in Figure 8.

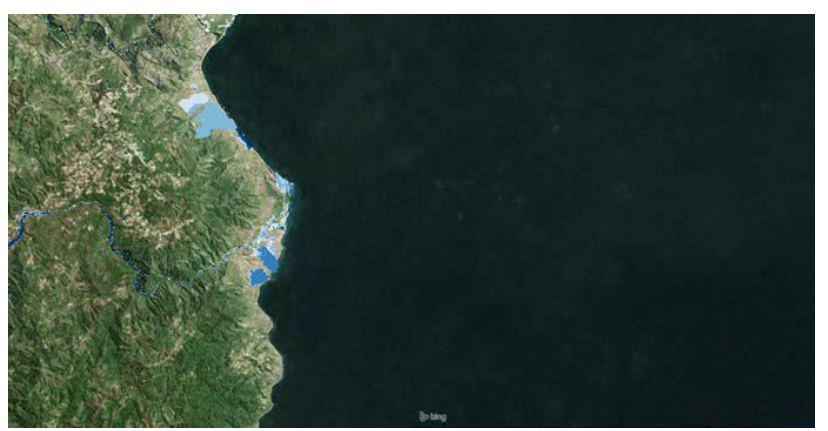

Figure 8 Erroneous inundations on the lake shore.

\section{Elevation offsets due to forests and urban areas}

Although TanDEM-X has a very high horizontal resolution, the DEM contains signals from objects in the field. A typical elevated feature is a forest. Examples of this effect on the floodmaps is shown inFigure 9, where a patch of commercial forest (encircled in red) is causing a dry patch of land that in reality would be inundated. Another artefact is buildings and urban areas (encircled in 
yellow). These offsets are hard to remove from the DEM without sophisticated correction algorithms.

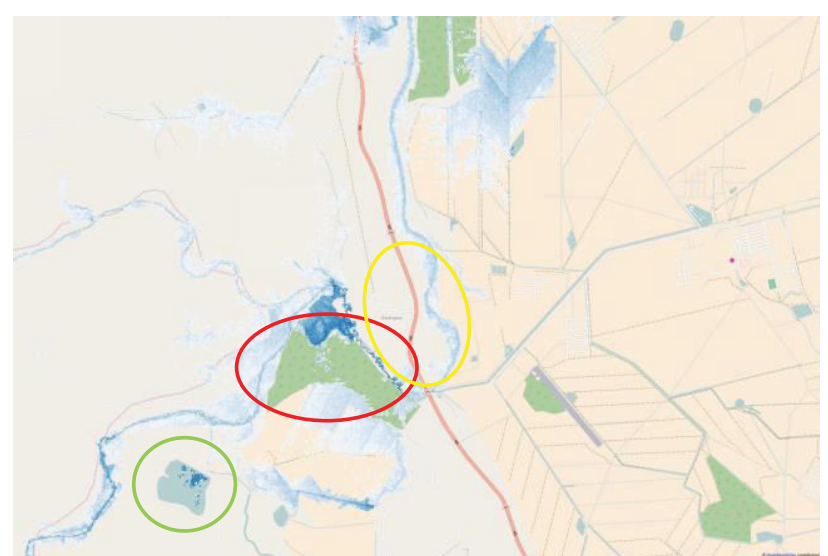

Figure 9 Effect of forest (red circle) and built-up areas (yellow circle). An open water body (indicated by a green circle) gives a noisy signal.

\section{Noise in open water bodies}

Permanent surface water gives a noisy signal in the raw TanDEM-X product, causing high and low peaks in the DEM. The effect of this can be seen in Figure 3.10. A small open water body shows scattered pixels with large differences in inundation depth over the pond. These water bodies are masked out in the processed DTM product, but this DTM is only available for the hotspot areas. Deltares is developing algorithms to mask out permanent surface water at $30 \mathrm{~m}$ resolution with LandSAT 8 imagery. However, these algorithms are not ready and cannot be applied to these flood maps yet. Moreover, the $30 \mathrm{~m}$ resolution water mask does not match the $12 \mathrm{~m}$ TanDEM-X resolution and will probably cause problems near the boundaries of these water bodies.

\subsection{Fluvial flood maps comparison- hotspots Karonga and Salima}

The fluvial flood maps obtained applying the HAND contour mapping can be compared, in correspondence to the hotspots, with those produced with the 2D model for the same sites.

Two models were developed for smaller (10x10km) hotspot areas near Karonga and Salima. Post-processed TanDEM-X digital terrain models (DTM) were used that were manually corrected by Airbus to remove elevated objects from the terrain (forests, buildings). A water mask was also applied in the case of Salima to suppress the noise from the open water of the river.

The Karonga 2D hydraulic model has a single inflow boundary condition (North Rukuru River). The Salima model has two upstream inflows (named Salima North and Salima South). The peak discharges for these inflows were derived from the annual maxima of the WFLOW model simulation with 32 years of EU-WATCH rainfall. The peak discharges for a range of return periods are given in Table 1 .

\begin{tabular}{|c|r|r|r|}
\hline T & Karonga & $\begin{array}{r}\text { Salima } \\
\text { (south) }\end{array}$ & $\begin{array}{c}\text { Salima } \\
\text { (north) }\end{array}$ \\
\hline 2 & 111 & 95 & 61 \\
\hline 2 & 226 & 191 & 123 \\
\hline 10 & 318 & 270 & 174 \\
\hline 20 & 414 & 352 & 226 \\
\hline 50 & 555 & 472 & 303 \\
\hline 100 & 668 & 569 & 365 \\
\hline 200 & 788 & 672 & 431 \\
\hline 500 & 945 & 815 & 522 \\
\hline 1000 & 1075 & 924 & 591 \\
\hline
\end{tabular}

Table 1 Peak discharges for upstream boundary conditions of Karonga and Salima models.

The shapes of the normalized hydrographs are shown in Figure 10. It was derived by averaging the four highest discharge peak hydrographs in the historical series. The design hydrograph for Karonga has a sharp peak of only a few days, because of the smaller catchment size (fast response).

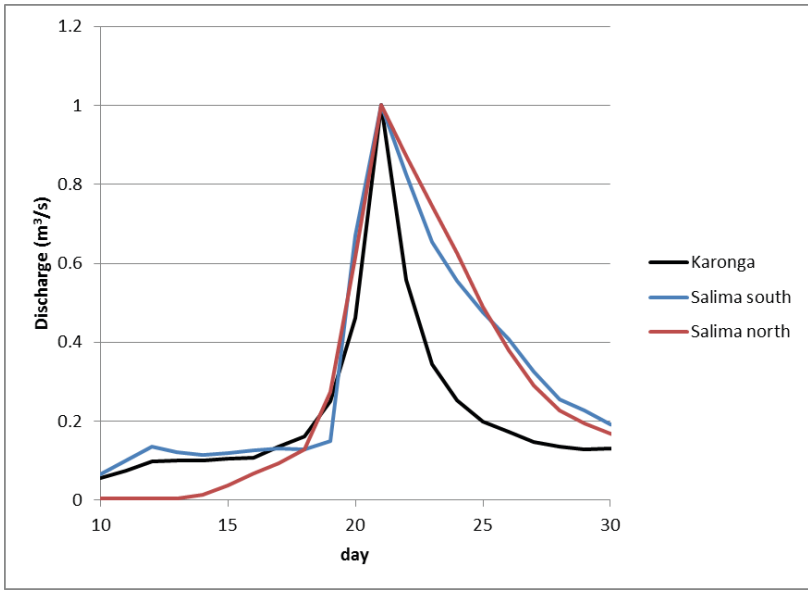

Figure 10 Normalized hydrograph for inflow boundary conditions of Karonga and Salima models.

The Karonga flood maps for $\mathrm{T}=10 \mathrm{yr}$ return period are shown in Figure 11. Both methods indicate that several areas north of the river will be flooded, although the HAND mapping method indicates smaller extents of flooding. Most of the inundations on the south bank are not reproduced by the HAND mapping method. The 2D hydraulic model predicts a diversion of the North Rukuru River towards the south, which connects to an existing stream that flows into Lake Malawi (on the right edge of the map). In the HAND mapping method this stream belongs to a different catchment, and because surface water cannot be redistributed from one catchment to another, the extent of the inundation on the southern bank is much smaller. The diversion of the North Rukuru River is an example of a complex flow pattern that cannot be reproduced by the HAND mapping method. The small 
isolated flood in the north is also an artefact of the HAND mapping method.
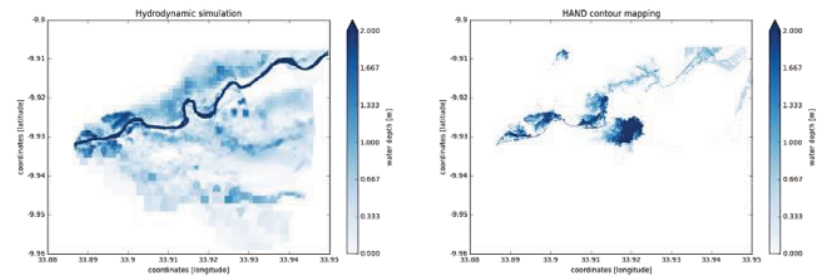

Figure $11 \mathrm{~T}=10 \mathrm{yr}$ flood maps for Karonga from 2D hydraulic model (left) and HAND contour mapping (right).

The Salima flood maps for $\mathrm{T}=10 \mathrm{yr}$ return period are shown in Figure 12. Several flooded areas match between the two maps, but there are also some important differences:

- The southern river branch just before the confluence is missing in the HAND map. This is due to the fact that the river is very shallow here and the TanDEM-X is very noisy. In the 2D model, the DTM is artificially lowered by the water mask.

- The shapes of the inundations on the south bank differ between the 2D model and the HAND map. In the 2D model, the water fills the flood plains just south of the main river. In the HAND map, the inundation follows the floodplains of a tributary. This is due to water being redistributed from the main river to flood plains of nearby tributaries.

- The isolated inundation in the North West corner of the HAND map is an artefact. Although this area is certainly floodable, the water depth for $\mathrm{T}=10$ is probably overestimated.
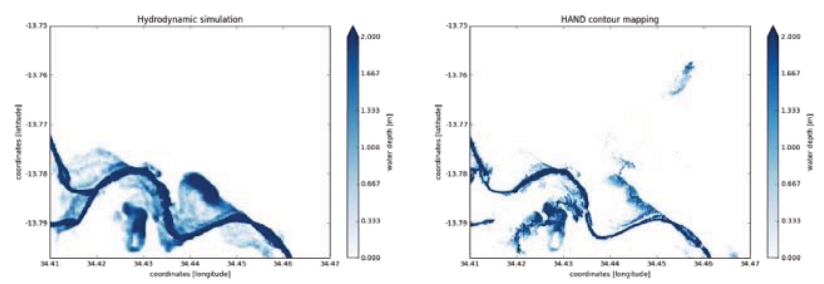

Figure $12 \mathrm{~T}=10 \mathrm{yr}$ flood maps for Salima from 2D hydraulic model (left) and HAND contour mapping (right).

\section{Exposure and modelling framework}

vulnerability

Hazard maps, developed according to the procedure described in the previous chapters, have been combined together with exposure and vulnerability data in order to carry on a damage computation. The following chapters provide background information on the different exposure layers and the collection of vulnerability functions used for the damage assessment.

\subsection{Exposure layers for Malawi}

Damage computation is subjected to the availability of exposure and vulnerability data at relative high resolution.
Access to high resolution base layer datasets such as $12 \mathrm{~m}$ resolution TanDEM-X allows a fairly detailed implementation of hazard models, aimed to predict the effects of floods.

However, in data-poor context, such as Malawi, exposure data have to rely on global datasets, which contain information only at national/provincial scale and cannot be directly used on damage computation.

To sort out this inconsistency, downscaling procedure has been applied to exposure data to make them consistent to high-resolution hazard layers.

This chapter provides background information on the preparation of exposure data of built-up area, population and annual crops for Malawi.

\subsubsection{Population}

The basic reference population layer for Malawi, expressed in terms of number of people per pixel, is the population layer developed by WorldPop ${ }^{5}$. This raster layer which represents the predicted number of people per $\sim 100 \mathrm{~m}$ pixel, obtained using as input census/population count datasets and mapping of settlements and applying the random forest (RF) model as described in Stevens, et al. (In Press). The result is then obtained adjusting the national total in order to match UN population division estimates (2012 revision).

\subsubsection{Built-up area}

A proper built-up layer is fundamental to downscale lumped data on different building typology. Built-up area for North and Central Malawi has been obtained merging information from 3 distinct layers:

- WorldPop population layer

- 2010 Land cover from MASDAP

- Global Human Settlement Layer

WorldPop population layer is the same population layer described in paragraph 4.1.1.

Malawi Landcover 2010 Scheme II ${ }^{6}$ has been developed from Landsat Imagery (30m by $30 \mathrm{~m}$ ) resolution using supervised classification. Classification Scheme II is such that it meets the country specific mapping standards and can be rolled back to the six IPCC land over categories for Scheme I: Forestland, Grassland, Wetland, Cropland, Settlement and Other land.

The Global Human Settlement Layer (GHSL) $^{7}$ is a product developed and maintained by the Joint Research Centre, the European Commission's in house science service, born with the aim to detect and initially characterize built-up areas based on average size (scale) of built-up structures. GHSL is derived from HR and VHR optical remotely sensed data through an automatic image classification. This product identifies the built-up areas, intended as any given area or geographical space where buildings can be found. The GHSL mask used as input to create the final built-up area layer for Malawi has been obtained from different GHSL layers at around 30

${ }^{5}$ http://www.worldpop.org.uk/

${ }^{6} \mathrm{http}: / / \mathrm{www} . \mathrm{masdap} . \mathrm{mw} /$ layers/geonode:malawi_landcov er_2010_schema_2

${ }^{7}$ http://ghslsys.jrc.ec.europa.eu 
meters of resolution, which have been merged to obtain the built-up area from 1975 till nowadays.

As a final result, a comprehensive built-up area layer has been built merging the following pieces:

-Class 12 (settlement) of the Land Cover layer

-Areas where are simultaneously present both population with a density higher than 5 people per cell and the classes 8 and 9 (perennial/annual cropland) of the land cover. This is done to identify urban settlement not reported in class 12 of the Land Cover.

-Areas where are simultaneously present both population with a density higher than 3 people per cell and the GHSL, apart from those which coincide with the classes 1,2,10,11 (dense forest, moderate forest, wetland, waterbody) of the Land Cover layer. This third element is added to consider also very small rural settlements and the scattered houses, which are ignored by the Land Cover layer, but well captured by the GHSL. The population mask is used as a control to avoid incorporating areas that the GHSL indicates as built-up while in reality are inhabited.

\subsubsection{Distribution of different building typologies}

The built-up area layer has been used as basis to distribute building data and obtain number of buildings belonging to the different building typologies present in North and Central Malawi. The reference building typologies are those introduced by the 2008 Population and Housing Census of Malawi [12]:

- PERMANENT: roof made of iron sheets, tiles, concrete or asbestos, and walls made of burnt bricks, concrete or stones.; these include caravans and tinned structures.

- SEMI-PERMANENT: lacking construction materials of a permanent structure for wall or roof.; these are structures, which are built of non-permanent walls such as sun-dried bricks or non-permanent roofing materials such as thatch.

- TRADITIONAL: both thatched roof and mud walls.

A survey on building stock in the three regions of Malawi (namely, North, Centre and South) has been conducted by the Global Earthquake Model inside the SSAHARA project ${ }^{8}$. In this study, buildings are subdivided according the following construction materials: burnt bricks, unburnt bricks, concrete, $\mathrm{mud} /$ wattle, reed/straw, wood/plank, other.

A correspondence between the three housing typologies and the classes of the census conducted by GEM has been identified and used to compute the number of permanent, semi-permanent and traditional housing typologies for both North and Central Malawi. Then, these buildings have been redistributed on the

\footnotetext{
8 http://www.globalquakemodel.org/what/regions/subsaharan-africa/
}

built-up areas of the two regions proportionally to the number of people.

The final result is a series of 6 raster files, a series of three (one for each housing typology) layers per region (North and Center), with a resolution of 30 meters, which represent the expected number of buildings of a certain typology per pixel, in one of the two considered areas.

\subsubsection{Agricultural production}

Exposure data on the agricultural production have been based on layers publicly available ${ }^{9}$.

Agricultural production layers provide information on the annual production (tons) for the following different annual crops: cassava, cotton, groundnuts, maize, pigeon peas, potatoes, rice, sorghum, tobacco.

The choice of crops typology to consider in the analysis has been made partially considering the relevance of the single crop in the Malawian production, and partially on the basis of data availability (not only for exposure characterization, but also for vulnerability description).

Layers resolution is about $9 \mathrm{~km} \times 9 \mathrm{~km}$. Those data have been downscaled taking into account the areas actually covered by annual crops at a much finer resolution of $30 \mathrm{~m}$, which have been extracted from the "Malawi Landcover 2010 Scheme II". The Land Cover maps have been developed from Landsat Imagery (30m by $30 \mathrm{~m}$ ) resolution using supervised classification. Image interpretation was done per scene. Images used for classification were selected based on seasonality, dry season images preferred.

With the downscaling procedure, the total amount of crop production of $9 \mathrm{~km} \mathrm{x} 9 \mathrm{~km}$ cell has been homogenously distributed in $30 \mathrm{~m} \times 30 \mathrm{~m}$ annual crop cells. The $30 \mathrm{~m} \times 30 \mathrm{~m}$ non-annual crop cells do not contribute to the production.

The result is of these two procedures is a 2-band raster file (geotiff), with the following information for each crop type:

- annual production of the crop in tons (in the $1^{\text {st }}$ band)

- $\quad$ price in USD/tons (in the $2^{\text {nd }}$ band)

\subsection{Vulnerability functions for Malawi}

Examples of vulnerability functions for crops depending on flood intensity (e.g., water level) for crop areas exist in literature, see for instance Dutta et al. [13]. These functions are usually defined for specific geographical areas and for a limited number of cultivation types.

In this context, another approach has been chosen, deriving crop loss functions by a loss estimation model based on the moment of the year in which the flood occurs. This choice is justified by the necessity of defining a model that could be applied to a specific area, without requiring an extensive amount of data.

The model that has been initially considered is the one adopted by the HAZUS Flood model [14], that is in turn based on the crop loss (damage) functions described in the AGDAM User's Manual [15]. Such functions

\footnotetext{
${ }^{9}$ http://www.masdap.mw/
} 
describe the course of crop losses (expressed as difference among investment and net revenue) in the different periods of cultivation cycle, identifying 5 topic moments, namely: the beginning of cultivation, the end of cultivation, the crop maturity, the beginning of harvest and the end of harvest. On the basis of these dates, four intervals are identified, in which crop loss $(\mathrm{D}(\mathrm{t})$ crop loss at day $t$ of the year - \% of maximum net revenue) is computed according to the specificity of the actions performed on the crop area.

A crop can be replanted if the flood occurs in the period of possible plantation, and if the soil dries in the same period. Thus, sometimes the previous function is modified by taking into account initial and final planting dates, see HEC-FIA [16]. At this point, to apply a simple loss model, some additional information (like cultivated area, normal annual yield, etc.) must be provided. This amount and variety of information makes the approach well adjustable to the specific crop and to the specific geographic area; at the same time, the objective of defining a model usable with a limited amount of specialized information is not reached.

Focusing on information on food crops, FAO provides country-level information on some specific cultivation types, such as sowing, growing and harvesting periods. Thus, a simplified model based on these periods is proposed. Like in the previously introduced functions, the production is considered to be growing until the end of growing season is reached; then, during the harvesting period the presence of crops in field decreases linearly.

Subsequently, a general crop production function is derived, and used as model for the definition of specific crop loss functions.

When possible, FAO data [17] have been preferred; in some specific cases other sources have been applied, specifically Negri and Porto [18] for tobacco, Nsanjama [19] for potatoes, MAFAP [20] for groundnuts, ICLARM - GTZ [21] for Cotton, Sweet Potato and Pigeon Peas.

Then, crop loss functions are applied whenever a water depth higher than zero is present on the cropland. A damage factor corresponding to the most flood prone period of the year (December-January) is considered.

Referring to buildings, Population and Housing Census of Malawi divides house types in the country into 3 categories [12]: permanent, semi-permanent and traditional.

In order to obtain vulnerability functions for these three typologies, the starting point has been the CAPRA flood vulnerability library, and more precisely to the functions adapted to Malawi. In this collection, vulnerability functions are defined for different construction materials (concrete, masonry, earth and wood) and for different number of stories of the considered building; as in this study the damage assessment can't be performed at single building level, a representative building height for the considered building stock has to be chosen, and consequently the most appropriate vulnerability function to be assigned.

In order to do so, the survey on building stock carried out by GEM inside the SSAHARA Project has been considered. In this study, buildings are subdivided in categories according the construction materials. A correspondence between these categories and the building materials considered in CAPRA, as well as the housing typologies, is reported in Table 2 .

\begin{tabular}{|c|c|c|c|c|c|c|c|}
\hline \multicolumn{4}{|c|}{ CAPRA - material } & \multirow[b]{2}{*}{ Building stock material } & \multicolumn{3}{|c|}{ Housing typologies } \\
\hline & 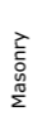 & 壳 & $\begin{array}{l}\text { ¿ } \\
\text { ڤ }\end{array}$ & & 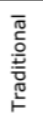 & 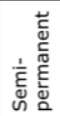 & 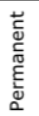 \\
\hline & $\mathrm{x}$ & & & Burnt bricks & & & $\mathrm{x}$ \\
\hline & $\mathrm{x}$ & $\mathrm{x}$ & & Unburnt bricks & & $\mathrm{x}$ & \\
\hline \multirow[t]{4}{*}{$\mathrm{x}$} & & & & Concrete & & & $\mathrm{x}$ \\
\hline & & $x$ & & Mud/wattle & $\mathrm{x}$ & & \\
\hline & & $\mathrm{x}$ & & Reed/straw & $\mathrm{x}$ & & \\
\hline & & & $\mathrm{x}$ & Wood/plank & $\mathrm{x}$ & & \\
\hline
\end{tabular}

Table 2 Correspondence between the housing typologies, the building materials considered in CAPRA and the building stock materials from GEM classification for Malawi.

These correspondences have been used in order to modify and weight the original CAPRA curves in order to synthetize a representative curve for each considered housing typology.

The vulnerability functions obtained have then been modified according to specific peculiarities of the three housing typologies. More precisely, characteristics such as the height of the main entrance/openings or the raising of the floor have been considered in order to finalize the curves.

\section{Damage assessment}

Damage is evaluated either as economic damage or in terms of affected people.

In case of economic damage evaluation, the replacement cost of the different feature typologies is obviously an essential parameter. The economic damage for each feature of each exposed category is generally evaluated as the product of the corresponding damage factor and economic value.

When considering the built-up area, the economic damage for each pixel is composed by the sum of the corresponding economic damage of the pixel in connection to the three different housing typologies. The total damage is thus evaluated trough the following expression:

Total damage $[\$]=\sum_{i=1}^{3}$ damage $_{i}{ }^{*} n b_{i} * r c_{i}[\$]$

Where:

$\bullet i=1, \ldots, 3$ are the different building typologies present in Malawi (permanent, semi-permanent and traditional)

- damage dis $_{i}$ the damage factor for the considered typology $i$, evaluated trough the damage curve, using as input the water depth $[\mathrm{m}]$ in the considered pixel

- $n b_{i}$ is the number of buildings of the considered typology $i$, present in the pixel

- $r c_{i}[\$]$ is the replacement cost for an "average" building belonging to typology 


\begin{tabular}{|c|c|c|c|c|}
\hline \multicolumn{5}{|c|}{ 2D MODEL } \\
\hline \multicolumn{5}{|c|}{ KARONGA } \\
\hline RP & Permanent & Semiperm. & Trad. & Population \\
\hline AAL & 218424 & 114568 & 48051 & 5466 \\
\hline 2 & 174395 & 62456 & 26294 & 875 \\
\hline 5 & 267132 & 109328 & 43532 & 9305 \\
\hline 10 & 413006 & 251538 & 102104 & 18170 \\
\hline 20 & 633493 & 468254 & 196530 & 28099 \\
\hline 50 & 1011742 & 834223 & 357806 & 36508 \\
\hline 100 & 1342263 & 1133587 & 495314 & 40092 \\
\hline 200 & 1699312 & 1438217 & 634354 & 42449 \\
\hline 500 & 2196041 & 1835717 & 815912 & 45039 \\
\hline 1000 & 2561783 & 2109558 & 941031 & 46732 \\
\hline \multicolumn{5}{|c|}{ MANGOCHI } \\
\hline $\mathrm{RP}$ & Permanent & Semiperm. & Trad. & Population \\
\hline$\overline{\mathrm{AAL}}$ & 9395 & 5645 & 2026 & 4850 \\
\hline 2 & $\mathbf{0}$ & $\mathbf{0}$ & $\mathbf{0}$ & $\mathbf{0}$ \\
\hline 5 & 3264 & 220 & 113 & 4110 \\
\hline 10 & 12715 & 4715 & 118 & 9537 \\
\hline 20 & 28761 & 19851 & 5708 & 11783 \\
\hline 50 & 56542 & 45874 & 20174 & 14968 \\
\hline 100 & 70372 & 57485 & 26021 & 16439 \\
\hline 200 & 85440 & 72122 & 32827 & 17235 \\
\hline 500 & 108517 & 93834 & 44417 & 18128 \\
\hline 1000 & 122254 & 105991 & 52084 & 19477 \\
\hline \multicolumn{5}{|c|}{ SALIMA } \\
\hline $\mathrm{RP}$ & Permanent & Semiperm. & Trad. & Population \\
\hline$\overline{\mathrm{AAL}}$ & 496644 & 141816 & 66301 & 2429 \\
\hline 2 & 419114 & 110068 & 49754 & 1072 \\
\hline 5 & 715348 & 201031 & 93243 & 4788 \\
\hline 10 & 1025794 & 328631 & 159654 & 7433 \\
\hline 20 & 1349624 & 437339 & 214196 & 8256 \\
\hline 50 & 1779401 & 549591 & 264224 & 8991 \\
\hline 100 & 2038616 & 602671 & 285524 & 9432 \\
\hline 200 & 2252509 & 645785 & 302532 & 9895 \\
\hline 500 & 2471145 & 695284 & $\mathbf{3 2 3 3 7 8}$ & 10492 \\
\hline 1000 & 2601091 & 728805 & $\mathbf{3 3 8 3 4 3}$ & 10903 \\
\hline
\end{tabular}

Table 3 Economic loss to the three building classes and number of affected people, for different return periods and as annual average loss, for the three hotspots, calculated with 2D model hazard maps.

$r c_{i}[\$]$ has been calculated considering an average replacement cost per square meter and an average building area for each typology.

The average building area for a given typology $i$ has been computed trough a weighted average of the areas of the building stock material classes (e.g. unburnt bricks, concrete, reed/straw...) which compose the considered typology. The relationships between typologies and building stock materials is reported in table Table 2.

\begin{tabular}{|c|c|c|c|c|}
\hline \multicolumn{5}{|c|}{ HAND COUNTOUR MAPPING } \\
\hline \multicolumn{5}{|c|}{ KARONGA } \\
\hline RP & Permanent & Semiperm. & Trad. & Population \\
\hline AAL & 228509 & 134032 & 59047 & 2229 \\
\hline 2 & $\mathbf{0}$ & $\mathbf{0}$ & $\mathbf{0}$ & $\mathbf{0}$ \\
\hline 5 & 252807 & 181318 & 80627 & 3650 \\
\hline 10 & 605018 & 362699 & 160801 & 4633 \\
\hline 20 & 980913 & 481923 & 210233 & 5459 \\
\hline 50 & 1454738 & 605161 & 259387 & 6419 \\
\hline 100 & 1755919 & 683350 & 290465 & 6826 \\
\hline 200 & 2019320 & 752868 & 318309 & 7281 \\
\hline 500 & 2318893 & 836124 & 352046 & 7813 \\
\hline 1000 & 2515472 & 893329 & 375595 & 8084 \\
\hline \multicolumn{5}{|c|}{ MANGOCHI } \\
\hline$\overline{\mathrm{RP}}$ & Permanent & Semiperm. & Trad. & Population \\
\hline AAL & 514 & 1583 & 685 & 483 \\
\hline 2 & $\mathbf{0}$ & $\mathbf{0}$ & $\mathbf{0}$ & $\mathbf{0}$ \\
\hline 5 & 235 & $\mathbf{0}$ & $\mathbf{0}$ & 639 \\
\hline 10 & 950 & 386 & 59 & 1257 \\
\hline 20 & 2290 & 1561 & 532 & 1761 \\
\hline 50 & 5469 & 4461 & 2040 & 2336 \\
\hline 100 & 9178 & 7742 & 3847 & 2768 \\
\hline 200 & 14359 & 12288 & 6485 & 3155 \\
\hline 500 & 23640 & 20270 & 10917 & 3705 \\
\hline 1000 & 32902 & 27836 & 15318 & 4005 \\
\hline \multicolumn{5}{|c|}{ SALIMA } \\
\hline $\mathrm{RP}$ & Permanent & Semiperm. & Trad. & Population \\
\hline AAL & 194930 & 71949 & 36470 & 1895 \\
\hline 2 & 0 & $\mathbf{0}$ & 0 & 0 \\
\hline 5 & 281815 & 109168 & 56036 & 3032 \\
\hline 10 & 473710 & 169785 & 85115 & 4085 \\
\hline 20 & 633394 & 216633 & 107352 & 5055 \\
\hline 50 & 831668 & 275963 & 135639 & 6258 \\
\hline 100 & 974000 & 318556 & 155797 & 7005 \\
\hline 200 & $\overline{1115688}$ & 358837 & 174627 & 7723 \\
\hline 500 & 1292907 & 408618 & 197537 & 8529 \\
\hline 1000 & 1417548 & 444313 & 214315 & 8964 \\
\hline
\end{tabular}

Table 4 Economic loss to the three building classes and number of affected people, for different return periods and as annual average loss, for the three hotspots, calculated with HAND contour mapping hazard maps.

Damage to crops has been evaluated with an equation similar to equation (2) developed for buildings, in which the production cost of each crop is multiplied by a damage factor estimated trough curves.

Affected population is identified counting the number of people inside the flooded area. 


\begin{tabular}{|c|c|c|c|}
\hline \multicolumn{4}{|c|}{ LOSS BUILDINGS [\$] } \\
\hline $\mathrm{RP}$ & North & Centre & North+Centre \\
\hline AAL & 485800 & 1254384 & 1740184 \\
\hline 5 & 652711 & 1617599 & 2214697 \\
\hline 10 & 961295 & 2173863 & 2959383 \\
\hline 20 & 1274944 & 3083964 & 4048491 \\
\hline 50 & 2107389 & 4825616 & 5959148 \\
\hline 100 & 39097456 & 7304852 & 7770157 \\
\hline 200 & 4781983 & 8516812 & 8948293 \\
\hline 500 & 5420592 & 9207136 & 9544642 \\
\hline 1000 & 5626240 & 9373584 & 9918664 \\
\hline \multicolumn{4}{|c|}{ LOSS CROPS [\$] } \\
\hline $\mathrm{RP}$ & North & Centre & North+Centre \\
\hline AAL & 12777174 & 8329082 & 21106256 \\
\hline 5 & 15919563 & 10075443 & 24769311 \\
\hline 10 & 17489688 & 10984943 & 26844738 \\
\hline 20 & 19067667 & 11784448 & 28860604 \\
\hline 50 & 21049695 & 14488235 & 31996125 \\
\hline 100 & 22871420 & 20154469 & 34918914 \\
\hline 200 & 24103987 & 23684983 & 37054963 \\
\hline 500 & 25341195 & 25856876 & 39253481 \\
\hline 1000 & 26803032 & 26160571 & 40951076 \\
\hline \multicolumn{4}{|c|}{ AFFECTED POPULATION [\$] } \\
\hline $\mathrm{RP}$ & North & Centre & North+Centre \\
\hline AAL & 21235 & 47255 & 68489 \\
\hline 5 & 30157 & 64764 & 89344 \\
\hline 10 & 34813 & 73209 & 98203 \\
\hline 20 & 35656 & 80811 & 106488 \\
\hline 50 & 38454 & 94459 & 117372 \\
\hline 100 & 43414 & 109924 & 131451 \\
\hline 200 & 45531 & 119409 & 141890 \\
\hline 500 & 46759 & 124359 & 151335 \\
\hline 1000 & 47283 & 125590 & 155563 \\
\hline
\end{tabular}

Table 5 Economic loss to buildings and crops in dollars and number of affected people, for different return periods and as annual average loss, for North and Central Malawi.

Results are presented here in terms of Annual Average loss and losses for some reference quantiles from 2 to 1000 years return period. These parameters are presented both at the level of the administrative units (North, Centre and North+Centre, the latter including the areas around Mangochi pertaining to the south administrative area) (Table 5) and for the Hotspots of Karonga, Salima and Mangochi (Table 3 and Table 4).

In the case of the hotspots a comparison between two different methodologies is presented. It interesting to see how the two methodologies give similar results in the case of Salima where the hazard maps, although showing distinct behaviours in some areas, have a comparable footprint. On the contrary, in Karonga the impact indicators almost double in the case of the more detailed approach this mainly due to the erroneous representation of the urbanized area of Karonga in the non-processed
DEM. That area is seen on the DEM as elevated due to the average quota of the buildings that is picked by the satellite sensor and in great part excluded from the exposed area. When a processed DTM is used jointly with at full 2D modelling approach that area that represent a good percentage of the asset in the area is included in the flooded area. This situation exacerbates in Mangochi where the difference in the risk indicators is one order of magnitude larger when analysed with the detailed approach. Here the main reason is actually ascribable to the flood modelling piece. Complex flow patterns are hardly reproduced by the HAND mapping method. Examples of complex flow patterns are river diversions and the blocking effect of levees or natural elevations in the landscape. In the first case, certain areas will stay dry in the fluvial flood map that are actually flooded. In the second case, the opposite happens.

All the results can be visualized trough the RASOR platform, which is available at www.rasor.eu. This platform allows to perform multi-hazard risk analyses for the full cycle of disaster management, including targeted support to critical infrastructures monitoring and climate change impact assessment.

\section{Conclusions}

A full probabilistic risk profile for Malawi has been carried out with respect to floods which are by fare the most frequent hazard in the Country. The paper concentrates on differences obtained in hazard and risk assessment in three hotspots in the Country where two modelling approach have been applied. This with the scope of understanding how cost-beneficial would be to investing in a more detailed DEM and modelling approach. Differences in Hazard can be important especially in areas with dense vegetation or dense urbanization where supervised post-processing of the DSM to obtain a high quality DTM delivers the highest impact. The difference in hazard reflects on the risk computations that show numbers that in some cases differ of an order of magnitude (Karonga, Mangochi), while in some other cases differences are definitely in the range of the process uncertainty (Salima). The changes in risk evaluations using both methods could justify the investment in densely populated areas where urbanization hampers the representativeness of the DEM and the full 2D modelling framework gives the biggest advantages. However, on large regions that are mainly rural the more detailed approach might not be the best option. A combined approach can be suggested as the most costbeneficial option in the case of Malawi.

\section{Acknowledgements}

This work has been funded by GFDRR-WB under the Development of National Disaster Risk Profiles for SubSaharan Africa project. We thank all GFDRR staff and especially Brenden Jongman for his continuous and competent support during the project development.

The RASOR platform has been developed within the Copernicus FP 7 RASOR project. 


\section{References}

1. Ward, P.J., Jongman, B., Weiland, F.S., Bouwman, A., Van Beek, R., Bierkens, M.F.P., Ligtvoet, W., Winsemius, H.C. [2013] A framework for global river flood risk assessments. Hydrology and Earth System Sciences, 8(4), doi:10.5194/hess-17-18712013.

2. Winsemius, H.C., Van Beek, L.P.H, Jongman, B., Ward, P. J., Bouwman, A. [2013] A framework for global river flood risk assessments. Hydrology and Hearth System Science, 17(5), doi:10.5194/hess-171871-2013

3. Weedon, G.P., Gomes, S., Viterbo, P., Shuttleworth, W.J., Blyth, E., Österle, H., Adam, J.C., Bellouin, N., Boucher, O., Best, M. [2011] Creation of the WATCH Forcing Data and Its Use to Assess Global and Regional Reference Crop Evaporation over Land during the Twentieth Century. Journal of Hydrometeorology, 12, 823-848 doi : 10.1175/2011JHM1369.1

4. Haddeland, I., Clark, D. B., Franssen,W., Ludwig, F., Voß, F., Arnell, N. W., Bertrand, N., Best, M., Folwell, S., Gerten, D., Gomes, S., Gosling, S.N., Hagemann, S., Hanasaki, N., Harding, R., Heinke, J., Kabat, P., Koirala, S., Oki, T., Polcher, J., Stacke, T., Viterbo, P., Weedon, G.P., Yeh, P. [2011] Multimodel estimate of the global terrestrial water balance: Setup and first results. Journal of Hydrometeorology, 12(5), pp.869-884.

5. Ngongondo, C., Chong-Yu, X., Tallaksen, L.M., Alemaw, B. (2015), Observed and simulated changes in the water balance components over Malawi, during 1971-2000. Quaternary International 369 , 7-16. http://dx.doi.org/10.1016/j.quaint.2014.06.028

6. Chow, V.T., Maidment D.R., Mays, L.W. [1988] Applied hydrology, Mc Graw-Hill.

7. Schellekens. J. [2013] OpenStreams: wflow documentation (release 0.91).

8. Verwey, A., Kernkamp, H. W. J., Stelling, G. S., Tse, M. L. \& Leung, W. C. [2011] Potential And Application Of Hydrodynamic Modelling On Unstructured Grids. In Proceedings of the Sixth International Conference on Asian and Pacific Coasts (APAC 2011) (pp. 1-8).

9. Kernkamp, H. W. J., Dam, A., Stelling, G. S. \& Goede, E. D. [2011] Efficient scheme for the shallow water equations on unstructured grids with application to the Continental Shelf. Ocean Dynamics, 61(8), 1175-1188. doi:10.1007/s10236011-0423-6.

10. Dunne, T., Leopold, L.B. [1978] Water in Environmental Planning. W.H. Freeman and Company, New York.

11. Nobre, A.D., Cuartas, L.A., Hodnett, M., Rennó, C.D., Rodrigues, G., Silveira, A., Waterloo, M., Saleska S. [2011] Height above the Nearest Drainage, a hydrologically relevant new terrain model. Journal of Hydrology, doi: 10.1016/j.jhydrol.2011.03.051
12. Lindstrom, N. [2014] Survey of urban poor settlements in Lilongwe. Actionaid.

13. Dutta, D., Herath, S., Musiake, H. [2003] A mathematical model for flood loss estimation. Journal of Hydrology, 277(1-2), 24-49, doi:10.1016/S0022F1694(03)00084F2

14. HAZUS-MH: Flood Model: User Manual, Department of Homeland Security Federal Emergency Manamegent Agency Mitigation Division Waschington, D.C.

15. AGDAM Agricultural Flood Damage Analysis User's Manual, US Army Corps of Engineers, Hydrologic Engineering Centre, 1985.

16. HEC-FIA Flood Impact Analysis - User's Manual, US Army Corps of Engineers, Hydrologic Engineering Centre, 2012.

17. http://www.fao.org/giews/countrybrief/country.jsp? code $=$ MWI

18. Negri, M., Porto, [2008] Burley Tobacco Clubs in Malawi: Nonmarket Institutions For Exports

19. Nsanjama, R. A. [1984] Report on Potato Production in Malawi. International Potato Course: Production, Storage, and Seed Technology. The Netherlands.

20. MAFAP [2012] Analysis of incentives and disincentives for groundnuts in Malawi.

21. ICLARM - GTZ [1991] The context of small-scale integrated agriculture-acquaculture systems in Africa: a case study of Malawi. 